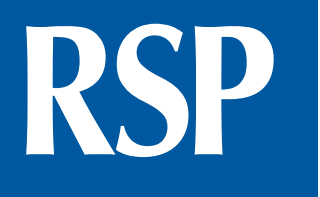

http://www.rsp.fsp.usp.br/
Revista de Saúde Pública

\section{Prevalência de transtorno mental comum entre trabalhadores canavieiros}

Polyana Felipe Ferreira da Costa', Solange Laurentino dos Santos", Marcelo Saturnino da Silva"I', Idê Gomes Dantas Gurgel ${ }^{\text {IV }}$

' Fundação Oswaldo Cruz. Instituto Aggeu Magalhães. Programa de Pós-Graduação em Saúde Pública. Recife, PE, Brasil

" Universidade Federal de Pernambuco. Departamento de Medicina Social. Recife, PE, Brasil

III Universidade Estadual da Paraíba. Departamento de Educação. Guarabira, PB, Brasil

iv Fundação Oswaldo Cruz. Instituto Aggeu Magalhães. Departamento de Saúde Coletiva. Recife, PE, Brasil

\section{RESUMO}

OBJETIVO: Estimar a prevalência de transtornos mentais comuns e analisar os fatores associados em trabalhadores migrantes e canavieiros.

MÉTODOS: Estudo transversal realizado com 110 trabalhadores. Os transtornos mentais comuns foram avaliados por meio do Self-Reporting Questionnaire (SRQ-20) e foram estudadas variáveis sociodemográficas, ocupacionais e de estilo de vida. Para detectar o uso abusivo de bebidas alcoólicas, foi utilizado o questionário CAGE.

RESULTADOS: A prevalência de transtornos mentais comuns afetou $40 \%$ dos trabalhadores e a associação mostrou significância estatística para a positividade no teste CAGE, adoecimento, falta ao trabalho e atendimento médico durante o período da safra.

CONCLUSÕES: A suspeita de casos de bebedores-problemas e os mecanismos de controle utilizados pela usina para os trabalhadores que faltam ou adoecem são fatores que podem causar transtornos mentais comuns.

DESCRITORES: Saúde da População Rural. Migrantes. Transtornos Mentais, epidemiologia. Fatores de Risco. Condições de Trabalho. Estudos Transversais.
Correspondência:

Polyana Felipe Ferreira da Costa

Rua Jacinto Alves de Carvalho, 67

Nossa Senhora da Penha

56903-360 Serra Talhada, PE, Brasil

E-mail: polyana.upe@gmail.com

Recebido: 1 mai 2016

Aprovado: 13 dez 2016

Como citar: Costa PFF, Santos SL, Silva MS, Gurgel IGD. Prevalência de transtorno mental comum entre trabalhadores canavieiros. Rev

Saude Publica. 2017;51:113.

Copyright: Este é um artigo de acesso aberto distribuído sob os termos da Licença de Atribuição Creative Commons, que permite uso irrestrito, distribuição e reprodução em qualquer meio, desde que o autor e a fonte originais sejam creditados. 


\section{INTRODUÇÃO}

Os transtornos mentais comuns (TMC) caracterizam-se por sintomas como fadiga, irritabilidade, esquecimento, dificuldade de concentração e queixas somáticas ${ }^{1}$. A sua identificação não significa a constatação de nenhum diagnóstico, apenas levantamentos de possíveis predisposições para o adoecimento mental ${ }^{2}$. A corrente de base epidemiológica se caracteriza por estudos voltados para a investigação quantitativa de categorias específicas de trabalhadores, no intuito de avaliar as condições concretas de trabalho, características das organizações e o perfil de adoecimento dos trabalhadores, buscando avaliar associações entre essas condições e as características laborais e o adoecimento observado ${ }^{3}$.

De acordo com Ludermir e Melo Filho ${ }^{4}$, a epidemiologia psiquiátrica tem identificado associação dos TMC a variáveis relativas às condições de vida e à estrutura ocupacional. Constitui-se, assim, um sério problema de saúde pública e apresenta impactos econômicos relevantes, em função das demandas geradas aos serviços de saúde e do absenteísmo no trabalhoa.

O trabalho nos canaviais exige muita força física e habilidades manuais com o instrumento de trabalho, o facão, ou podão. O trabalhador precisa, dentre outras coisas, obedecer ao ritmo de trabalho prescrito, acompanhar a intensidade da produção e vencer os perigos e insalubridades próprios desse tipo de trabalho ${ }^{5}$. O trabalho manual na colheita de cana-de-açúcar representa riscos à saúde dos trabalhadores, devido ao calor intenso, à constante radiação solar, à poeira proveniente do solo e à presença de animais peçonhentos. Há, também, risco acentuado de acidentes de trabalho em decorrência do manuseio do facão ${ }^{6}$.

Sabe-se que, além das situações de risco decorrentes do processo e das relações de trabalho, grande parte desses sujeitos, na condição de migrante, também vivenciam situações de vulnerabilidade nos espaços de moradia, trajeto e nas próprias relações com os "nativos" nos espaços de trabalho ou lazer?.

O alcoolismo entre os trabalhadores rurais é uma resposta ao estresse laboral crônico que aparece quando falham as estratégias de enfrentamento que o indivíduo, habitualmente, emprega para manejar os estressores laborais. Comportando-se como uma variável mediadora entre o estresse percebido e suas consequências, o alcoolismo é um hábito tipicamente manifestado por meio de sintomas psicológicos, estando estreitamente relacionado com insatisfações no trabalho.

Nesse contexto, destaca-se a realidade que se faz presente na microrregião do Pajeú, Sertão de Pernambuco e partes da microrregião da Serra da Teixeira, no Estado da Paraíba, onde grande parcela da população economicamente ativa vem lançando mão da migração sazonal, tendo como destino, sobretudo, o trabalho na colheita de cana-de-açúcar na microrregião de São José do Rio Preto, interior do Estado de São Paulo,10.

${ }^{a}$ Faker JN. A cana nossa de cada dia: saúde mental e qualidade de vida em trabalhadores rurais de uma usina de álcool e açúcar de Mato Grosso do Sul [dissertação].Campo Grande: Universidade Católica Dom Bosco; 2009 [citado 30 jul 2017]. Disponível em: http://site.ucdb.br/public/ md-dissertacoes/8075-a-cananossa-de-cada-dia-saudemental-e-qualidade-de-vida-emtrabalhadores-rurais-de-umausina-de-alcool-e-acucar-demato-grosso-do-sul.pdf ${ }^{\mathrm{b}}$ Instituto Brasileiro de Geografia e Estatística. Brasil em Síntese: cidades e estados brasileiros. Rio de Janeiro: IBGE; s.d. [citado 25 set 2017]. Disponível em: http:// www.cidades.ibge.gov.br

No presente artigo, busca-se identificar a prevalência de TMC e analisar os fatores associados em trabalhadores migrantes e canavieiros.

\section{MÉTODOS}

Trata-se de estudo descritivo de corte transversal, realizado com trabalhadores migrantes do sertão paraibano e pernambucano, que laboram na colheita da cana-de-açúcar na região de São José do Rio Preto, interior do Estado de São Paulo, mais especificamente nos municípios de Novo Horizonte e Mendonça. Esses municípios apresentam como característica comum unidades industriais de uma mesma empresa do setor sucroalcooleiro, que se tornou conhecida como uma das principais usinas que recruta a mão de obra diretamente na região de origem desses trabalhadores.

Dados do Censo Demográfico do Instituto Brasileiro de Geografia e Estatística (2010) mostram, nos resultados da amostra sobre a migração, que cerca de 4,9\% e 6,5\% da população que residia nos municípios de Novo Horizonte e Mendonça, respectivamente, denominaram que a região Nordeste era o seu lugar de nascimentob. 
A população de referência foi constituída por todos os trabalhadores com vínculo empregatício na usina estudada (110 cortadores de cana), no período da pesquisa (julho a setembro de 2014), e que apresentavam como local de origem municípios do sertão paraibano e pernambucano. O número de participantes $(\mathrm{n}=110)$ do estudo correspondeu a todos os trabalhadores contratados na presente safra.

Para a coleta de dados, foram utilizados um questionário com dados sociodemográficos e ocupacionais e o Self-Reporting Questionnaire (SRQ-20). O SRQ-20 é um instrumento que avalia ocorrência de TMC, desenvolvido por Harding et al. ${ }^{11}$ e validado no Brasil por Mari e Willians em 1986, apresentando sensibilidade de $85 \%$ e especificidade de $80 \%$. Pesquisa realizada em Pernambuco, tendo como padrão ouro a entrevista psiquiátrica, obteve uma sensibilidade de $62 \%$ e especificidade de $80 \%^{12}$.

O SRQ-20 é composto de 20 itens sobre sintomas físicos e psíquicos, com escala de respostas dicotômicas (sim ou não), para detecção de transtornos mentais comuns. Cada resposta afirmativa pontua com o valor 1 para compor o escore final por meio do somatório desses valores. Os escores obtidos estão relacionados à probabilidade de presença de transtorno não psicótico, variando de 0 (nenhuma probabilidade) a 20 (extrema probabilidade). Os pontos de corte são de 7/8, independentemente do sexo, conforme descrito por Gonçalves et al. ${ }^{13}$, ou seja, as respostas que apresentarem escore $\geq 7$ foram consideradas como indicadores de possível TMC.

O estudo investigou os diferentes aspectos da vida dos trabalhadores, como as condições sociodemográficas (idade, escolaridade, estado civil, número de filhos), condições de moradia (tipo de moradia e vínculo entre o trabalhador e os outros residentes), trabalho (número de safras trabalhadas, salário médio por mês na última safra, morbidade relacionada ao trabalho, falta ao trabalho e atendimento médico durante a safra) e estilo de vida (uso de bebidas alcoólicas, tabaco e outras drogas). Para detectar o uso abusivo de bebidas alcoólicas, o questionário CAGE foi incluído na categoria estilo de vida.

O teste CAGE é também um questionário padronizado, composto por quatro perguntas. Sua denominação é derivada das iniciais das palavras-chave de cada pergunta do original em inglês: 1) alguma vez sentiu que deveria diminuir ou parar de beber? (Cut down?); 2) as pessoas o aborrecem porque criticam o seu modo de beber? (Annoying by criticism?);3) sente-se culpado pela maneira como costuma beber? (Guiltierabout drinking?); 4) costuma beber pela manhã para diminuir o nervosismo e a ressaca? (Eye-opener drink?). O CAGE é utilizado como teste de triagem para o chamado bebedor-problema, suspeito de ser dependente de álcool, adotando-se o ponto de corte em duas ou mais respostas positivas para as quatro questões do teste. Apresenta alta sensibilidade, especificidade e valores preditivos, tanto na sua versão em inglês, como na versão em português ${ }^{14}$.

O procedimento de coleta de dados foi realizado pelo preenchimento do questionário com dados sociodemográficos e ocupacionais, seguida pela aplicação do SRQ-20 e do teste CAGE. O contato com o setor de recursos humanos da usina foi importante para mapear os locais de moradia dos trabalhadores; assim, os instrumentos foram aplicados de forma individual nas moradias ou espaços de lazer dos trabalhadores. Para realizar a análise quantitativa, foi utilizado o programa EpiInfo for Windows, versão 3.5.1. Os trabalhadores foram caracterizados a partir dos dados sociodemográficos e ocupacionais e as variáveis de prevalência do TMC foram descritas por meio de medidas de frequência, tendência central e dispersão, sendo apresentadas por tabelas.

Em seguida, foi realizado o cruzamento entre as variáveis e TMC com o intuito de identificar existência de possíveis associações, por meio do teste qui-quadrado de Pearson ou do teste exato de Fisher. Utilizou-se como categoria de referência, de cada uma das variáveis analisadas, ter apresentado menor prevalência. A magnitude da associação de cada variável com a presença de TMC foi identificado pela razão de prevalência à significância estatística pelo intervalo de confiança de 95\%, obtidos por regressão logística. 
Tabela 1. Caracterização sociodemográfica e ocupacional da população estudada. $(n=110)$

\begin{tabular}{|c|c|c|c|}
\hline Variável & Categoria & $\mathbf{n}$ & $\%$ \\
\hline \multirow[t]{4}{*}{ Idade (anos) } & $18-29$ & 69 & 62,7 \\
\hline & $30-39$ & 25 & 22,7 \\
\hline & $40-49$ & 11 & 10,0 \\
\hline & Acima de 50 & 5 & 4,6 \\
\hline \multirow[t]{3}{*}{ Estado civil } & Solteiro & 53 & 48,2 \\
\hline & Casado & 38 & 34,5 \\
\hline & Divorciado & 19 & 17,3 \\
\hline \multirow[t]{5}{*}{ Número de filhos } & Nenhum & 59 & 53,7 \\
\hline & Apenas 1 & 24 & 21,8 \\
\hline & 2 & 14 & 12,7 \\
\hline & 3 & 8 & 7,3 \\
\hline & 4 ou mais & 5 & 4,5 \\
\hline \multirow[t]{3}{*}{ Sabe ler/escrever } & Sim & 72 & 65,4 \\
\hline & Não & 8 & 7,3 \\
\hline & Só assina o nome & 30 & 27,3 \\
\hline \multirow[t]{3}{*}{ Escolaridade } & Nenhuma & 9 & 8,2 \\
\hline & Ensino fundamental & 83 & 75,5 \\
\hline & Ensino médio & 18 & 16,3 \\
\hline \multirow[t]{4}{*}{ Tempo no corte da cana (anos) } & $1-5$ & 59 & 53,6 \\
\hline & $6-10$ & 38 & 34,6 \\
\hline & $11-15$ & 10 & 9,1 \\
\hline & $16-20$ & 3 & 2,7 \\
\hline \multirow[t]{2}{*}{ Renda familiar (salário mínimo) } & $1-2$ & 51 & 46,4 \\
\hline & $2-3$ & 59 & 53,6 \\
\hline \multirow[t]{2}{*}{ Tipo de moradia } & Cedida pela usina & 98 & 89,1 \\
\hline & Alugada pelos trabalhadores & 12 & 10,9 \\
\hline \multirow[t]{3}{*}{ Vínculo com outros moradores } & Trabalhadores & 67 & 60,9 \\
\hline & Parentes & 33 & 30,0 \\
\hline & Esposa & 10 & 9,1 \\
\hline \multirow[t]{2}{*}{ Alcoolismo } & Faz uso & 85 & 77,3 \\
\hline & Não faz uso & 25 & 22,7 \\
\hline \multirow[t]{2}{*}{ CAGE } & Positivo & 25 & 22,7 \\
\hline & Negativo & 85 & 77,3 \\
\hline
\end{tabular}

CAGE: Cut down, Annoyed, Guilty, Eye-opener

Tabela 2. Distribuição dos grupos de sintomas do SRQ-20 por afirmativas positivas entre trabalhadores migrantes canavieiros, 2014.

\begin{tabular}{llcc}
\hline TMC & \multicolumn{1}{c}{ Questões } & $\mathbf{n}$ & $\%$ \\
\hline Humor depressivo ou ansioso & Q4 Assusta com facilidade? & 37 & 33,5 \\
& Q6 Sente-se nervoso, tenso ou preocupado? & 65 & 59,1 \\
& Q9 Sente tristeza ultimamente? & 80 & 72,7 \\
& Q10 Tem chorado mais do que de costume? & 18 & 16,4 \\
\multirow{5}{*}{ sintomas somáticos } & Q1 Dores de cabeça frequente? & 57 & 51,8 \\
& Q2 Falta de apetite? & 73 & 66,4 \\
& Q3 Dorme mal? & 55 & 50,0 \\
& Q5 Tremores na mão? & 66 & 60,0 \\
& Q7 Má digestão? & 46 & 41,8 \\
& Q19 Sensações desagradáveis no estômago? & 28 & 25,5 \\
Decréscimo da energia vital & 1 & 0,9 \\
& Q8 Dificuldade de pensar com clareza? & 0 & 0 \\
& Q11 Dificuldade de realizar com satisfação atividades diárias? & 38 & 34,5 \\
& Q12 Dificuldade para tomar decisões? & 99 & 90,0 \\
& Q13 Dificuldade no serviço (trabalho penoso, sofrido)? & 74 & 67,3 \\
& Q18 Sente-se cansado o tempo todo? & 21 & 19,1 \\
& Q 20 Cansa com facilidade? & 0 & 0 \\
& Q14 É incapaz de desempenhar um papel útil em sua vida? & 1 & 0,9 \\
& Q15 Tem perdido o interesse pelas coisas? & 0 & 0 \\
& Q16 Sente-se uma pessoa inútil, sem préstimo? & 4 & 3,6 \\
\hline
\end{tabular}

TMC: transtornos mentais comuns 
Tabela 3. Distribuição da prevalência dos TMC por variáveis sociodemográficas e ocupacionais.

\begin{tabular}{|c|c|c|c|c|}
\hline Característica & Prevalência (\%) & RP & IC95\% & $p$ \\
\hline \multicolumn{5}{|l|}{ Faixa etária (anos) } \\
\hline $18-29$ & 40,6 & 1,49 & $0,54-4,07$ & 0,311 \\
\hline $30-39$ & 40,0 & 1,47 & $0,50-4,31$ & 0,366 \\
\hline $40-49$ & 27,3 & $*$ & $*$ & * \\
\hline$\geq 50$ & 60,0 & 2,20 & $0,66-7,31$ & 0,241 \\
\hline \multicolumn{5}{|l|}{ Estado civil } \\
\hline Solteiro & 37,7 & 1,19 & $0,57-2,52$ & 0,634 \\
\hline Casado & 47,4 & 1,50 & $0,71-3,15$ & 0,259 \\
\hline Divorciado & 31,6 & * & $*$ & * \\
\hline \multicolumn{5}{|l|}{ Filhos } \\
\hline Sim & 39,2 & $*$ & * & * \\
\hline Não & 40,7 & 0,96 & $0,61-1,53$ & 0,876 \\
\hline \multicolumn{5}{|l|}{ Escolaridade } \\
\hline Nenhum & 44,4 & 2,67 & $0,75-9,45$ & 0,139 \\
\hline Ensino fundamental & 44,6 & 2,67 & $0,93-7,72$ & 0,028 \\
\hline Ensino médio & 16,7 & * & $*$ & * \\
\hline \multicolumn{5}{|l|}{$N^{\circ}$ de safras } \\
\hline 1 a 5 & 42,4 & 1,27 & $0,25-6,47$ & 0,621 \\
\hline 6 a 10 & 36,8 & 1,11 & $0,21-5,78$ & 0,701 \\
\hline 11 a 15 & 40,0 & 1,20 & $0,20-7,05$ & 0,685 \\
\hline 16 a 20 & 33,3 & $*$ & $*$ & $*$ \\
\hline \multicolumn{5}{|l|}{ Renda familiar } \\
\hline 1-2 salários & 41,2 & 1,06 & $0,67-1,67$ & 0,815 \\
\hline 2-3 salários & 38,9 & $*$ & * & * \\
\hline \multicolumn{5}{|c|}{ Vínculo com outros moradores } \\
\hline Outros trabalhadores & 36,5 & * & * & * \\
\hline Parentes & 40,0 & 1,04 & $0,63-1,73$ & 0,881 \\
\hline Esposa & 50,0 & 1,30 & $0,65-2,60$ & 0,359 \\
\hline \multicolumn{5}{|l|}{ Alcoolismo } \\
\hline Sim & 41,2 & 1,14 & $0,64-2,05$ & 0,643 \\
\hline Não & 36,0 & * & * & * \\
\hline \multicolumn{5}{|l|}{ CAGE } \\
\hline Sim & 38,6 & 3,19 & $1,51-6,74$ & 0,001 \\
\hline Não & 12,1 & * & * & * \\
\hline \multicolumn{5}{|l|}{ Relação saúde-trabalho } \\
\hline Sim & 50,9 & 1,80 & $1,09-2,96$ & 0,016 \\
\hline Não & 28,3 & * & * & * \\
\hline \multicolumn{5}{|l|}{ Faltou ao trabalho } \\
\hline Sim & 54,4 & 2,36 & $1,36-4,09$ & 0,0008 \\
\hline Não & 24,5 & $*$ & * & $*$ \\
\hline \multicolumn{5}{|l|}{ Atendimento médico } \\
\hline Sim & 48,5 & 1,78 & $1,03-3,06$ & 0,026 \\
\hline Não & 27,3 & $*$ & $*$ & $*$ \\
\hline
\end{tabular}

TMC: transtornos mentais comuns; CAGE: Cut down, Annoyed, Guilty, Eye-opener * Grupo de referência.

O estudo foi aprovado pelo Comitê de Ética em Pesquisa do Centro de Ciências da Saúde da Universidade Federal de Pernambuco (CAAE 27225414.2.0000.5208), respeitando-se o que dispõe a Resolução 466/12, do Conselho Nacional de Saúde e a declaração de Helsinque (1964). Todos os participantes assinaram o termo de consentimento livre e esclarecido. 


\section{RESULTADOS}

Estudaram-se 110 trabalhadores migrantes, cuja média de idade foi de 29,6 (DP =9,4) anos. A descrição dos dados sociodemográficos e ocupacionais é apresentada na Tabela 1.

Na análise por grupo dos sintomas (Tabela 2), observou-se que, na categoria humor depressivo ou ansioso, o maior número de respostas concordantes foi para a afirmativa "sente-se triste ultimamente", com $72,7 \%$ de respostas positivas, seguida de "sente-se nervoso, tenso ou preocupado" $(59,1 \%)$.

A prevalência global de TMC entre os trabalhadores estudados foi de $40 \%(\mathrm{n}=44)$, segundo o SRQ-20 (escore de corte 7/8). A distribuição da prevalência dos TMC por variáveis sociodemográficas está apresentada na Tabela 3.

Em relação aos fatores associados ao TMC, os trabalhadores que apresentaram positividade na avaliação do CAGE, os que durante a safra tiveram algum problema de saúde relacionado ao trabalho, os que relataram faltar ao trabalho e aqueles que receberam atendimento médico durante o período de trabalho apresentaram maior chance de serem suspeitos para o TMC.

\section{DISCUSSÃO}

Todos os trabalhadores estudados eram do sexo masculino. A preferência pela mão de obra masculina está atrelada ao novo contexto da mecanização nas usinas de cana-de-açúcar, uma vez que foram intensificados o ritmo e a jornada de trabalho, demandando do trabalhador muita força física e habilidade manual para acompanhar o ritmo da produção e competir com a máquina ${ }^{15}$.

A faixa etária predominante entre os participantes foi de 18-29 anos (62,7\%). Esse achado confirma o que outros autores ${ }^{15,16}$ enfatizam, ou seja, a preferência por parte das usinas canavieiras de contratarem homens jovens, por disporem de mais energia e serem mais produtivos. Isso se explica por ser o corte da cana-de-açúcar um trabalho penoso, que acaba não favorecendo a inserção de trabalhadores mais velhos. Tal fenômeno justifica também o tempo reduzido de permanência do trabalhador nos canaviais - no presente estudo, $88,2 \%$ dos trabalhadores apresentavam um a 10 anos de safra no corte da cana.

De acordo com Novaes et al. ${ }^{15}$, ser jovem também tem um diferencial. Significa ter uma específica disposição para o trabalho, alavancada pelo momento do ciclo da vida quando via de regra - prevalece a busca, o desejo de "ser alguém na vida", motivação indispensável para os jovens enfrentarem a rotina e a disciplina no trabalho. Afinal, para eles, filhos de agricultores, o trabalho é o único caminho para a realização de projetos pessoais e familiares.

A escolaridade na população estudada foi outro fator que merece destaque, pois a maioria $(75,5 \%)$ dos sujeitos pesquisados possuía até o Ensino Fundamental - 49,1\% relataram não o ter concluído e apenas $26,4 \%$ declararam ter finalizado essa etapa. Além disso, 27,3\% dos trabalhadores "só sabem assinar o nome". O baixo perfil de escolaridade observado entre os trabalhadores migrantes é similar ao perfil encontrado nos estados da Paraíba e Pernambuco. Dados da Pesquisa Nacional por Amostras de Domicílios , realizada pelo IBGE em 2013, mostram que pessoas de 25 anos ou mais de idade que se encontram entre as categorias "sem instrução ou menos de um ano" até "oito anos de estudo" correspondem a 64,2\% no estado da Paraíba e 58,6\% no de Pernambuco.

${ }^{\mathrm{c}}$ Instituto Brasileiro de Geografia e Estatística. PNAD - Pesquisa Nacional por Amostra de Domicílios: síntese de indicadores sociais. Rio de Janeiro: IBGE; 2011 [citado 30 julho 2017]. Disponível em: ftp://ftp.ibge.gov.br/Indicadores_ Sociais/Sintese_de_Indicadores Sociais_2014/pdf/educacao.pdf

Como consequência do baixo índice de escolaridade, pode-se observar a dificuldade de inserção desses jovens em outros setores do mercado de trabalho ou a não estabilidade na profissão de cortador de cana. Diante do atual processo de mecanização, exige-se que o trabalhador tenha maior escolaridade e qualificação para manusear as novas tecnologias, como operar colhedeiras e conduzir tratores e caminhões, e assumir novos postos de trabalho, como mecânicos especializados em manutenção e reparo de máquinas agrícolas ${ }^{6}$. 
${ }^{\mathrm{d}}$ Instituto Brasileiro de Geografia e Estatística PNAD - Pesquisa Nacional por Amostra de Domicílios Contínua. Rio de Janeiro: IBGE; 2014 [citado 30 jul 2007]. Disponível em: ftp.ibge.gov.br/Trabalho_e_ Rendimento/Pesquisa_Nacional_ por_Amostra_de_Domicilios_ continua/Renda_domiciliar_per_ capita_2014/Renda_domiciliar_ per_capita_2014.pdf

e Duarte GJ. Transtornos mentais comuns em trabalhadores rurais no corte da cana-de-açúcar,

Santa Helena de Goiás/Goiás [dissertação]. Goiânia: Pontifícia Universidade Católica de Goiás; 2010 [citado 30 jul 2017]. Disponível em: http://tede2. pucgoias.edu.br:8080/bitstream/ tede/3141/1/GUILHERME\%20 JOSE\%20DUARTE.pdf

${ }^{\text {fS}}$ Santos AP. O moinho satânico do agronegócio canavieiro no Brasil: dependência e superexploração do trabalho na região de Ribeirão Preto - SP [tese]. Campinas: Instituto de Filosofia e Ciências Humanas da Universidade Estadual de Campinas; 2013 [citado 30 jul 2017]. Disponível em: http:// repositorio.unicamp.br/jspui/ bitstream/REPOSIP/280877/1/ Santos_AdrianoPereira_D.pdf
O perfil de renda média mensal observada entre os trabalhadores canavieiros teve maior concentração $(53,6 \%)$ no estrato que corresponde de dois a três salários mínimos (R\$1.449-R\$2.172), o que se mostra superior à renda mensal (per capita) nos estados de Pernambuco e Paraíba, que se encontra na faixa de $\mathrm{R} \$ 802,00$ a $\mathrm{R} \$ 682,00^{\mathrm{d}}$.

A possibilidade de adquirir uma renda mais alta, que possibilite satisfazer as suas necessidades e, ao mesmo tempo, realizar seus sonhos, favorece a procura pelo trabalho nos canaviais paulistas, visando a, sobretudo, "ganhar dinheiro", "comprar uma moto", uma "casa", "ser bem visto pelos familiares". Sabendo-se que um jovem da zona rural, dificilmente, consegue concretizar esses sonhos trabalhando nos locais de origem, o caminho escolhido, geralmente, é o da migração para os canaviais ou outras atividades, como a construção civil ou colheita do café ou da laranja.

Em relação ao tipo de moradia, o tipo mais relatado pelos trabalhadores foi a casa cedida ou alugada pela usina $(89,1 \%)$. De acordo com Cover ${ }^{10}$, no processo de migração para o corte de cana, há basicamente duas modalidades de moradia para os trabalhadores: aquelas em casas alugadas pelos próprios trabalhadores nas cidades (em bairros próximos às usinas), no caso da migração realizada com a família; e a moradia em alojamentos ou casas alugadas pela usina, para trabalhadores que migram sozinhos.

\section{Saúde Mental dos Trabalhadores}

A prevalência global de TMC (40\%) foi superior ao encontrado em outros estudos que tinham como referência a população de trabalhadores rurais canavieiros. Estudo realizado por Fakera, em uma usina de açúcar e álcool, no município de Novo Andradina, MS, identificou uma prevalência de $12 \%$. Duarte ${ }^{e}$, em trabalho realizado com cortadores de cana-de-açúcar do município de Santa Helena de Goiás, na região de Goiânia, GO, encontrou prevalência de 33,1\%.

A baixa prevalência encontrada na pesquisa realizada por Faker ${ }^{a}$ pode ser explicada pelo fato de que a população estudada não era apenas de cortadores de cana, mas também de trabalhadores do corte mecânico. Além disso, a coleta de dados foi realizada nos espaços de trabalho ou trajeto para os canaviais e sempre com a presença de dois funcionários do setor técnico administrativo da usina ${ }^{a}$, o que pode ter influenciado as respostas dos trabalhadores (viés de informação).

Entretanto, os achados deste estudo se aproximam de outras pesquisas realizadas em comunidades rurais e com agricultores em geral. Em comunidade rural, Costa e Ludermir ${ }^{17}$ encontraram $36 \%$ de prevalência de TMC entre agricultores da zona da Mata de Pernambuco, e Faria ${ }^{18}$ encontrou $38 \%$ em agricultores da serra gaúcha.

Em relação à análise por grupo de sintomas do SRQ-20, observou-se que a maior concentração de respostas positivas (90\%) foi para a pergunta "dificuldade no serviço - trabalho penoso, sofrido". O trabalho do corte manual da cana-de-açúcar é descrito por Santos ${ }^{f}$ como um trabalho precário, a partir da percepção do trabalhador.

A percepção desses trabalhadores acerca do processo de trabalho e seus efeitos sobre a saúde é a de que o trabalho nos canaviais é duro, sofrido e prejudicial e que isso decorre das condições de trabalho, mas também do esforço que são obrigados a fazer para atingir as médias de produtividade exigidas pelas usinas. Essa característica de um trabalho intensificado, cujo ritmo de produção é sempre acelerado, pode trazer riscos imediatos para a saúde do trabalhador, devido a acidentes de trabalho. Entretanto, pode também gerar um desgaste irreversível a longo prazo, pois o esforço é contínuo e o tempo de recuperação física e manutenção da força de trabalho é limitado e insuficiente.

Seligmann-Silva ${ }^{19}$ mostra como o cansaço físico está diretamente relacionado ao cansaço mental.

A fadiga mental é indissociável da fadiga física. [...] Nos casos em que o cansaço se acumula ao longo do tempo, surgem os quadros que têm sido designados como fadiga crônica ou fadiga patológica, 
marcada não apenas pelo cansaço que não cede ao sono diário, mas também pelos distúrbios do sono, pela irritabilidade, pelo desânimo e, às vezes, por dores diversas e perdas de apetite.

O desânimo também foi relatado pelos trabalhadores. No grupo humor depressivo ou ansioso, a afirmativa "sentiram-se tristes nos últimos dias" foi bastante relevante entre os trabalhadores (72,7\%). Acredita-se que grande parte desses trabalhadores, em razão do distanciamento de seu meio social e familiar, vivenciam cotidianamente o drama da saudade dos seus entes queridos.

No grupo de sintomas somáticos, chama-se a atenção para a afirmativa "falta de apetite", com $66 \%$ de respostas afirmativas. A falta de apetite relatada pelos cortadores de cana também pode estar relacionada ao modo como os alimentos são preparados e armazenados até o momento do consumo nos canaviais, pois foi possível observar que a alimentação era preparada pelos próprios trabalhadores, geralmente altas horas da noite, constando, na maior parte dos casos, apenas de feijão, farinha, arroz e carne. Além disso, muitas vezes, os trabalhadores se deparavam com a comida estragada no horário do almoço.

A maior frequência de respostas negativas foi encontrada no grupo de sintomas depressivos, sendo relatado o maior número de respostas positivas na afirmativa "tem tido ideia de acabar com a vida", com $3,6 \%$.

\section{Fatores Associados ao TMC}

A prevalência de TMC foi mais elevada entre os trabalhadores que se encontravam na faixa etária acima de 50 anos (60\%), casados (47,4\%), que não possuíam filhos (40,7\%), com um a cinco anos de safra no corte da cana-de-açúcar (42,4\%), na faixa de um a dois salários mínimos (41,2\%), que dividiam a moradia no local de destino com a esposa (50\%), e que faziam uso de bebidas alcoólicas (41,2\%). No entanto, nenhuma dessas variáveis apresentou significância estatística $(\mathrm{p}>0,05)$.

Quanto às variáveis que se mostraram significativas, os trabalhadores que apresentaram positividade na avaliação do CAGE, os que tiveram algum problema de saúde relacionado ao trabalho, os que relataram faltar ao trabalho e aqueles que receberam atendimento médico durante o período de trabalho apresentaram uma chance, respectivamente, de $3,19(p=0,001)$, $1,80(\mathrm{p}=0,016), 2,36(\mathrm{p}=0,0008)$ e $1,78(\mathrm{p}=0,026)$ vezes de serem suspeitos para o TMC.

Acredita-se que a forte associação entre a suspeição do TMC e a avaliação positiva do CAGE (trabalhadores identificados como bebedores-problema) podem ocasionar uma desorganização dos investimentos afetivos provocados pelas organizações do trabalho, colocando em perigo a saúde mental dos trabalhadores. De acordo com Dejours ${ }^{20}$, o alcoolismo pode ser considerado uma estratégia defensiva, utilizada como uma saída individual frente à ansiedade relativa à sobrevivência e que pode ocasionar um destino mental e somático particularmente grave.

O TMC também esteve associado aos trabalhadores que relataram terem sido acometidos por algum problema de saúde relacionado ao trabalho. Entre os principais adoecimentos descritos pelo grupo de trabalhadores com suspeição para TMC destacam-se: cortes, dores na coluna e articulações, alergia na pele, infecção intestinal, pneumonia, hipertensão, urolitíase e labirintite. Todos esses trabalhadores conseguiram explicar, a partir de suas experiências, o nexo causal entre o trabalho nos canaviais e os respectivos adoecimentos.

Para o homem, a doença corresponde sempre à ideologia da vergonha de parar de trabalhar, pois o corpo só pode ser aceito no silêncio dos órgãos, somente o corpo que trabalha, o corpo produtivo do homem, é aceito ${ }^{21}$. Tal dificuldade de assumir que o corpo está doente encontra uma barreira ainda maior quando se trata de homens nordestinos, que foram criados em uma cultura essencialmente machista, na qual é comum a reprodução da ideia de que "homem que é homem não adoece", "não sente dor". Talvez, conviver com o adoecimento longe dos familiares e mais próximos de outros homens que também foram adestrados nesse mesmo meio social seja difícil e possa trazer alguma consequência para a sua saúde mental. 
Em relação ao absenteísmo no trabalho, pôde-se observar que a maioria dos trabalhadores faltou por ter sido acometida de algum problema de saúde. No entanto, também foram identificadas outras razões, como: uso abusivo de bebida alcoólica, separação do casamento e cursos na autoescola para realizar o exame de habilitação. Qualquer motivo que leve o trabalhador a faltar resulta em penalidades por parte da usina, pois a mesma dispõe de mecanismos de controle para lidar com os faltosos. Os trabalhadores que costumam faltar têm seus nomes incluídos em uma lista, conhecida como "lista negra", elaborada pela usina; consequentemente, ficam impossibilitados de serem contratados para a próxima safra ${ }^{10}$.

A última variável que se mostrou significativa foi a procura por atendimento médico, que também demanda aceitar que o corpo produtivo está doente e precisa de cuidado, que se faz necessário faltar ao trabalho e pedir um atestado médico. Sabe-se que a usina utiliza mecanismos para controlar o número de atestados ${ }^{\mathrm{b}} \mathrm{e}$ isso pode resultar em redução do rendimento financeiro ou, até mesmo, comprometer a vaga no próximo ano.

Os resultados obtidos neste estudo devem ser avaliados com cautela por causa das possíveis limitações do estudo transversal. Pode ter havido viés de seleção, pois avaliamos apenas quem estava trabalhando no momento da pesquisa. Portanto, quem adoeceu e perdeu o emprego não entrou no estudo (viés de sobrevivência). Também não se pode descartar a hipótese de causa reversa, ou seja, não é possível identificar se os TMC influenciaram os fatores associados ou vice-versa.

Outra limitação foi que o instrumento SRQ-20, utilizado na coleta de dados, não foi autoaplicado, pois a maioria dos trabalhadores apresentaram muitas dificuldades relacionadas à escolaridade. Então, a participação da pesquisadora, neste momento, pode ter levado a viés de informação. Adicionalmente, houve a redução do número de trabalhadores que participaram da pesquisa, pois, diante do avanço do processo de mecanização e do fenômeno da seca que atingiu a região Sudeste no ano de 2014, a maior parte dos trabalhadores foram demitidos antes da metade da safra. Isso dificultou a análise dos dados, pois amplos intervalos de confiança foram obtidos, o que diminui a precisão das estimativas.

\section{REFERÊNCIAS}

1. Goldberg D, Huxley P. Commom mental disorders: a bio-social model. London: Tavistock; 1992.

2. Lima MEA. Os problemas de saúde na categoria bancária: considerações acerca do estabelecimento do nexo causal. Bol Saude. 2006 [citado 29 jul 2017];20(1):57-68. Disponível em: http://www.boletimdasaude.rs.gov.br/conteudo/1355/os-problemas-de-saude-na-categoriabancaria:-consideracoes-acerca-do-estabelecimento-do-nexo-causal

3. Araújo TM, Graça CC, Araújo E. Estresse ocupacional e saúde: contribuições do modelo demanda-controle. Cienc Saude Coletiva. 2003;8(4):991-1003. https://doi.org/10.1590/S1413-81232003000400021

4. Ludermir AB, Melo Filho DA. Condições de vida e estrutura ocupacional associadas a transtornos mentais comuns. Rev Saude Publica. 2002;36(2):213-21. https://doi.org/10.1590/S003489102002000200014

5. Alves F. Migração de trabalhadores rurais do Maranhão e Piauí para o corte de cana em São Paulo: será esse um fenômeno causal ou recorrente da estratégia empresarial do Complexo Agroindustrial Canavieiro. In: Novaes JR, Alves F. Migrantes: trabalho e trabalhadores no Complexo Agroindustrial Canavieiro (os heróis do agronegócio brasileiro). São Carlos: EDUFSCar; 2007.

6. Rocha FLR, Marziale MHP, Robazzi MLCC. A pobreza como fator predisponente ao adoecimento de trabalhadores do corte da cana-de-açúcar. Rev Latino-Am Enfermagem. 2007;15 Nºspec:736-41. https://doi.org/10.1590/S0104-11692007000700004

7. Moraes MS, Priuli RMA. Migração e saúde: os trabalhadores do corte da canade-açúcar. Rev Intedis Mobil Hum. 2011 [citado 29 jul 2017];19(37):231-45. Disponível em: http://www.csem.org.br/remhu/index.php/remhu/article/view/285/260

8. Beck Filho JA, Amorim AM, Fraga-Maia H. Consumo de álcool entre os trabalhadores do corte da cana-de-açúcar: prevalência e fatores associados. Rev Pesq Fisioter. 2016;6(3):306-16. https://doi.org/10.17267/2238-2704rpf.v6i3.952 
9. Costa PFF, Silva MS, Santos SL. O desenvolvimento (in)sustentável do agronegócio canavieiro. Cienc Saude Coletiva. 2014;19(10):3971-80. https://doi.org/10.1590/1413-812320141910.09472014

10. Cover M. O 'tranco da roça' e a 'vida no barraco': um estudo sobre os trabalhadores migrantes no setor do agronegócio canavieiro [dissertação]. João Pessoa: Centro de Humanidades da Universidade Federal de Campina Grande; 2011 [citado 29 jul 2017]. Disponível em: http:// www.reformaagrariaemdados.org.br/sites/default/files/2011\%20Maciel\%20Cover\%20UFCB.pdf

11. Harding TW, Arango MV, Baltazar J, Climent CE, Ibrahim HHA, Ladrido-Ignacio L, et al. Mental disorders in primary health care: a study of their frequency and diagnosis in four developing countries. Psychol Med. 1980;10(2):231-42. https://doi.org/10.1017/S0033291700043993

12. Ludermir AB. Inserção produtiva, gênero e saúde mental. Cad Saude Publica. 2000;16(3):647-59. https://doi.org/10.1590/S0102-311X2000000300013

13. Gonçalves DM, Stein AT, Kapczinski F. Avaliação de desempenho do Self-Reporting Questionnaire como instrumento de rastreamento psiquiátrico: um estudo comparativo com o Structured Clinical Interview for DSM-IV-TR. Cad Saude Publica. 2008;24(2):380-90. https://doi.org/10.1590/S0102-311X2008000200017

14. Masur J, Monteiro MG. Validation of the "CAGE" alcoholism screening test in a Brazilian psychiatric inpatient hospital setting. Braz J Med Biol Res. 1983;16(3):215-8.

15. Novaes JR, Alves F, organizadores. Migrantes: trabalho e trabalhadores no Complexo Agroindustrial Canavieiro (os heróis do agronegócio brasileiro). São Carlos: EDUFSCar; 2007.

16. Silva MS, Menezes MA. Homens que migram, mulheres que ficam: o cotidiano das esposas, mães e namoradas dos migrantes sazonais do Município de Tavares. In: Scott P, Cordeiro R, Menezes M, organizadores. Gênero e geração em contextos rurais. Florianópolis: Mulheres; 2010. v.1, p.279-311.

17. Costa AG, Ludermir AB. Transtornos mentais comuns e apoio social: estudo em comunidade rural da Zona da Mata de Pernambuco, Brasil. Cad Saude Publica. 2005;21(1):73-9. https://doi.org/10.1590/S0102-311X2005000100009

18. Faria NMX, Facchini LA, Fassa AG, Tomasi E. Estudo transversal sobre saúde mental de agricultores da Serra Gaúcha (Brasil). Rev Saude Publica. 1999;33(4):391-400. https://doi.org/10.1590/S0034-89101999000400011

19. Seligmann-Silva E. Desgaste mental no trabalho dominado. Rio de Janeiro: Cortez; 1994.

20. Dejours C. A banalização da injustiça social. 7.ed. Rio de Janeiro: Fundação Getúlio Vargas; 2006.

21. Dejours C. A loucura do trabalho: estudo da psicopatologia do trabalho. 5.ed. São Paulo: Cortez; 1992.

Financiamento: Conselho Nacional de Desenvolvimento Científico e Tecnológico (CNPq - Processo 481754/2013-0). Fundação de Amparo à Ciência e Tecnologia de Pernambuco (FACEPE - Processo APQ15984.06/15).

Contribuição dos Autores: Concepção e planejamento do estudo, coleta dos dados, análise e interpretação dos dados: PFFC, SLS, MSS. Elaboração e revisão do manuscrito: PFFC, SLS, IGDG. Todos os autores aprovaram a versão final do artigo e assumem a responsabilidade pública pelo conteúdo.

Conflito de Interesses: Os autores declaram não haver conflito de interesses. 